\title{
Review: antibiotics reduce wound infections and intra-abdominal abscesses in patients having appendectomy
}

Andersen BR, Kallehave FL, Andersen HK. Antibiotics versus placebo for preventing postoperative infection after appendectomy. Cochrane Database Syst Rev 2001;(3):CD001439 (latest version Feb 26 2001).

\section{QUESTION: Does antibiotic treatment reduce postoperative infections in patients having appendectomy?}

\section{Data sources}

Studies were identified by searching the Cochrane Controlled Trials Register (issue 1, 2001), Medline (January 1966 to September 2000), EMBASE/Excerpta Medica, and the Cochrane Colorectal Cancer Group trials register (September 2000), and by reviewing bibliographies of identified studies.

\section{Study selection}

Randomised controlled trials (RCTs) in which treatment with antibiotics (given before, during, or after surgery) was compared with placebo in patients with suspected appendicitis who were having appendectomy and if $\geqslant 1$ of the following outcomes was reported: wound infection, postoperative intra-abdominal abscess, length of hospital stay, and mortality. Studies that compared antibiotics with a control group receiving no treatment were excluded unless blinding was adequate.

\section{Data extraction}

2 independent reviewers extracted data using a standard form. Individual trials were assessed for methodological quality (randomisation method, blinding, and loss to follow up). Authors were contacted if the report provided insufficient detail.

\section{Main results}

44 RCTs and controlled clinical trials (9298 patients, age range 3 mo to $94 \mathrm{y}$ ) were included in the meta-analyses, 12 of which had $>1$ treatment arm. The most commonly tested antibiotics were cephalosporin and imidazole derivatives.

Overall, antibiotics reduced the rate of wound infections more than did placebo (table). Results were similar for subgroup analyses by type of appendicitis (simple or complicated), timing of intervention (pre-, intra- or postoperative administration of antibiotics), and dosage (single or multiple). Antibiotics reduced intra-abdominal abscesses overall (table); subgroup analyses by type of appendicitis, timing of intervention, and dosage were not significant. Results for length of hospital stay were equivocal. Only 2 trials reported mortality as an outcome, with a total of 3 deaths; therefore, no direct comparison of results was done.

7 trials $(\mathrm{n}=776)$ focused exclusively on children $0-15$ years of age and found no difference between antibiotics and placebo for overall wound infection or intraabdominal abscess. 4 trials $(\mathrm{n}=679)$ compared topical antibiotics with placebo and found no difference for overall wound infection.

\section{Conclusion}

In patients having appendectomy, antibiotics compared with placebo reduce the risk of wound infection and intra-abdominal abscess.

Antibiotics v placebo in patients having appendectomy*

\begin{tabular}{|c|c|c|c|c|c|}
\hline \multirow[b]{2}{*}{ Outcomes } & \multirow{2}{*}{$\begin{array}{l}\text { Number of } \\
\text { comparisons (n) }\end{array}$} & \multicolumn{2}{|c|}{$\begin{array}{l}\text { Weighted events } \\
\text { rate }\end{array}$} & \multirow[b]{2}{*}{$\operatorname{RRR}(95 \% \mathrm{Cl})$} & \multirow[b]{2}{*}{ NNT (Cl) } \\
\hline & & Antibiotics & Placebo & & \\
\hline Wound infection & 71 (8643) & $5.3 \%$ & $14.6 \%$ & $60 \%$ (55 to 65$)$ & 11 (10 to 13$)$ \\
\hline $\begin{array}{l}\text { Intra-abdominal } \\
\text { abscess }\end{array}$ & $20(4468)$ & $0.7 \%$ & $1.7 \%$ & $51 \%(18$ to 70$)$ & 100 (59 to 334$)$ \\
\hline
\end{tabular}

*Abbreviations defined in glossary; RRR, NNT, and $\mathrm{Cl}$ calculated from data in article. A fixed effects model was used for all analyses. Follow up data were not consistently reported in individual trials.

\section{COMMENTARY}

The meta-analysis by Anderson $e t$ al adds evidence to the debate on the efficacy of antibiotics and their use in surgical patients, specifically those having appendectomies. Concerns regarding the increase in antibiotic resistant microorganisms may have reduced prophylactic use of antibiotics for surgical patients; however, this review provides strong evidence from a large number of studies that antibiotics prevent postoperative wound infection in people having appendectomy. Current practice varies among practitioners and this review, plus related evidence built into an evidence-based guideline, would be helpful in informing clinical decision making about antibiotic use. More research is needed to determine the most effective antibiotic and optimal dosing regimen.

It is interesting to note that no reduction in infection was associated with antibiotic use in a subgroup of children aged $0-15$ years. The explanation for the lack of effect in children is unclear, but the data presented in this review also suggest that children not treated with antibiotics have lower rates of infection than adults. Furthermore, there was no subgroup analysis by type of surgery, and antibiotics may have a different effect in laparoscopic versus open surgery. Such an analysis would have been informative given that a historical cohort study of children found that laparoscopic appendectomy for a perforated appendix was more likely to result in postoperative intra-abdominal abscess than open surgery $(25 \% v 2 \%){ }^{1}$

From a clinical perspective, the findings of this meta-analysis support the use of antibiotics in patients having an appendectomy. The effect is remarkably consistent irrespective of whether the antibiotics are given pre-, intra- or postoperatively. Furthermore, the effect was also seen in a reduction in length of stay, which is likely to result in substantial cost savings if antibiotic use is widely implemented for these patients.

Heidi L Kalinowski, RN, CNP, MSN Nurse Practitioner, Surgery St John Hospital and Medical Center Detroit, Michigan, USA

1 Krisher SL, Browne A, Dibbins A, et al. Intra-abdominal abscess after laparoscopic appendectomy for perforated appendicitis. Arch Surg 2001;136:438-41. 